\title{
Left ventricular pump efficiency in long-term mitral regurgitation assessed by means of left ventricular-arterial coupling relations
}

\begin{abstract}
The left ventricular-arterial coupling relationship was used in patients with long-term mitral regurgitation to test the hypothesis that the low impedance left atrial contribution to left ventricular ejection obscures an impairment in left ventricular-arterial coupling and forward left ventricular pump efficiency. Twenty-two control patients and 26 patients with long-term mitral regurgitation were studied. Micromanometer left ventricular pressures and radionuclide angiograms for left ventricular volumes were acquired over a range of loading conditions. Left ventricular-arterial coupling was assessed by the ratio of left ventricular chamber elastance, $E_{\text {es, }}$, to total arterial elastance, $E_{a}$. Forward left ventricular pump efficiency was calculated as the ratio of forward left ventricular stroke work to the corresponding pressure-volume area. There was a progressive decrease in $\mathrm{E}_{\mathrm{es}}$ in the patients with long-term mitral regurgitation $(p<0.001)$, but there was no significant difference in $\mathrm{E}_{\mathrm{a}}$ in comparison to the control patients. Consequently, $E_{e g} / E_{a}$ demonstrated a progressive decrease $(p<0.001)$. Although the efficiency of performing total left ventricular stroke work was only reduced when left ventricular contractile function was severely impaired $(p<0.001)$, there was a progressive reduction in left ventricular pump efficiency for performing forward left ventricular stroke work in the patients with long-term mitral regurgitation $(p<0.001)$. Further, normalized left ventricular stroke work was reduced for any left ventricular-arterial coupling ratio in the patients with long-term mitral regurgitation compared with the control patients. These data indicate that despite the outward evidence for normal left ventricular ejection in patients with long-term mitral regurgitation, a progressive deterioration in left ventricular contractile state leads to impaired left ventricular-arterial coupling and to an impairment in the efficiency of performing forward left ventricular stroke work. Once the left ventricle begins to dilate in patients with long-term mitral regurgitation, the progressive deterioration in left ventricular-arterial coupling and pump efficiency suggests that an earlier consideration of mitral valve surgery may be warranted to preserve left ventricular contractile function. (AM HEART J 1994;127:1324-35.)
\end{abstract}

Mark R. Starling, MD Ann Arbor, Mich.

As the ventricle dilates, left ventricular ejection fraction remains normal in patients with long-term mitral regurgitation as a result of the low impedance to ejection provided by the left atrium. This is related to the preservation of normal end-systolic stress and to the uncoupling of end systole from end ejection. ${ }^{1,2}$ In spite of an outward appearance of normal left ventricular ejection, the left ventricle dilates, it

From the Division of Cardiology, Department of Internal Medicine, University of Michigan and Veterans Administration Medical Centers.

Supported by NIH R01 HL-36450 from the National Heart, Lung, and Blood Institute, Bethesda, Md.; the Veterans Administration, Washington, D.C.; and the Kughn Clinical Research Center (M01-RR00042) from the National Institutes of Health, Bethesda, Md.

Received for publication June 14, 1993; Sept. 10, 1993.

Reprint requests: Mark R. Starling, MD, Department of Internal Medicine, Division of Cardiology, 2215 Fuller Road, Ann Arbor, MI 48105.

4/1/53386 becomes more spherical, and there is an increase in the left ventricular end-diastolic radius:thickness ratio, suggesting that eccentric hypertrophy may not be adequate. ${ }^{3}$ In addition, recent data from animal models of chronic mitral regurgitation and in humans with long-term mitral regurgitation have demonstrated that left ventricular contractile function may deteriorate despite a normal ejection fraction. ${ }^{4,5}$ These data suggest that left ventricular pump function may be impaired if it were not for the left atrial contribution to the maintenance of left ventricular ejection.

The interaction of the left ventricle with the systemic arterial system has not been evaluated in patients with long-term mitral regurgitation because of the difficulty of separating systemic from regurgitant flow and the absence of a suitable theoretic framework to assess left ventricular pump function. 
Applying radionuclide angiography to the calculation of left ventricular-arterial coupling relations provides an opportunity to assess this interaction more specifically within an appropriate theoretic framework. ${ }^{6,7}$ Accordingly, the left ventricular-arterial coupling relationship was used in control subjects and in patients with long-term mitral regurgitation to test the hypothesis that the effects of the low impedance left atrium on left ventricular ejection obscures an impairment in left ventricular-arterial coupling and forward left ventricular pump efficiency.

\section{METHODS}

Patients. The study population consisted of 22 control subjects who were referred for cardiac catheterization to evaluate an atypical chest pain syndrome, and 26 patients with long-term mitral regurgitation who were referred for cardiac catheterization to evaluate the hemodynamic severity of their valvular heart disease. The control population had clinical characteristics that were similar to those of a larger cohort of 29 patients, who have been reported elsewhere. ${ }^{8}$ In brief, these 22 subjects had a normal physical examination, electrocardiogram, chest radiograph, and at cardiac catheterization had normal left ventricular pressures, volumes, ejection fractions, masses, and coronary arteriograms.

Patients with long-term mitral regurgitation included 25 men and one woman, with an age range of 38 to 72 years (mean \pm SD $53 \pm 10$ years). The cause of the mitral regurgitation in these patients was rheumatic is five, redundant mitral leaflets in 19 with associated ruptured chordal structures with flail in seven of the 19 and associated endocarditis in two of the 19, and unknown causalogy in two. Eight patients were in clinical class I, seven were in class II, 10 were in class III, and one was in class IV. All of these patients had a physical examination consistent with severe mitral regurgitation, were in normal sinus rhythm at electrocardiography, had left ventricular dilation with an end-diastolic dimension of $60 \mathrm{~mm}$ or more on a two-dimensionally targeted M-mode echocardiogram, and had normal coronary arteries and severe angiographic mitral regurgitation at cardiac catheterization.

Protocol. All patients provided written informed consent for this investigation on forms approved by the Human Studies Committees at the University of Michigan or at Veterans Administration Medical Centers in Ann Arbor, Michigan. All medications were withheld for 24 hours before cardiac catheterization. After diagnostic right and left heart catheterization, a bipolar pacing catheter was placed in the right atrial appendage to maintain heart rate constant throughout the protocol. A micromanometer left ventricular catheter (Millar Instruments, Inc., Houston, Texas) was positioned to measure high-fidelity aortic and left ventricular pressures; red blood cells were tagged with technetium-99m for radionuclide angiography. Micromanometer left ventricular pressures and gated equilibrium radionuclide angiograms were acquired in duplicate during multiple left ventricular loading conditions produced by steady-state infusions of either methoxamine or nitroprusside. All patients completed this protocol without complications.

Hemodynamics. Micromanometer aortic and left ventricular pressures were recorded for 10 to 20 cardiac cycles at the beginning, middle, and end of each radionuclide acquisition. The left ventricular pressure waveforms were averaged, digitized at a variable sampling frequency, and interpolated to correspond with each radionuclide frame throughout the cardiac cycle. The program developed for analyzing the micromanometer pressure signals in our laboratory has been described elsewhere. ${ }^{9,10}$

Radionuclide angiography. Gated equilibrium radionuclide angingrams were acquired for $30 \mathrm{msec}$ frames throughout the cardiac cycle for 250 cardiac cycles. During the midportion of each radionuclide acquisition, a $2 \mathrm{ml}$ blood sample was drawn and was later counted for $2 \mathrm{~min}$ utes. The time delay was recorded for decay correction. At the completion of the protocol, a distance measurement was obtained for attenuation correction. Absolute radionuclide left ventricular volumes were calculated frameby-frame from background-subtracted, hand-drawn region-of-interest left ventricular count data that were standardized for frame duration, cardiac cycles acquired, decay-corrected blood sample counts, and attenuation. ${ }^{11-13}$

Data analysis. Corresponding micromanometer left ventricular pressures and radionuclide left ventricular volumes for each loading condition were plotted to obtain multiple pressure-volume loops for each patient. The pressure-volume loops for a representative patient with long-term mitral regurgitation are shown in Fig. 1. The maximal pressure-volume ratio from each pressure-volume loop was subjected to linear regression analysis to obtain a slope $\left(\mathrm{E}_{\text {es }}\right)$ reflecting left ventricular chamber elastance, a relatively load-independent index of left ventricular contractility. ${ }^{14-17}$ To obtain effective arterial elastance $\left(E_{a}\right)$, end-systolic pressure $\left(\mathrm{P}_{\mathrm{ez}}\right)$ was divided by radionuclide left ventricular stroke volume in the control subjects or by forward stroke volume $\left(\mathrm{SV}_{\mathrm{f}}\right)$ in the patients with long-term mitral regurgitation. End-systolic pressure $\left(\mathrm{P}_{\mathrm{es}}\right)$ was defined as the left ventricular pressure at the maximum pressure-volume ratio. To obtain left ventricular $\mathrm{SV}_{\mathrm{f}}$ in the patients with mitral regurgitation, total left ventricular stroke output was divided by the regurgitant index to partition it into forward and regurgitant left ventricular stroke volume. A modification of the methods of Maddahi et al. ${ }^{18}$ and Sorensen et al. ${ }^{19}$ was used for obtaining right ventricular stroke counts, which were then used to calculate regurgitant index by dividing left ventricular stroke counts by right ventricular stroke counts. Coupling of the left ventricle and systemic arterial system was then expressed for each patient as the ratio of $\mathrm{E}_{\mathrm{es}} / \mathrm{E}_{\mathrm{a}}{ }^{6}$

Two important assumptions were made in this investigation. First, consistent with the data from Sunagawa et al. ${ }^{6}$ in isolated left heart preparations, and with the results of theoretic studies by Burkoff and Sagawa, ${ }^{7}$ we assumed that maximal left ventricular output or work occurred when $E_{e s}$ was equivalent to $E_{a}$ for any value of $E_{e s}$ in our control subjects and in patients with long-term mitral re- 


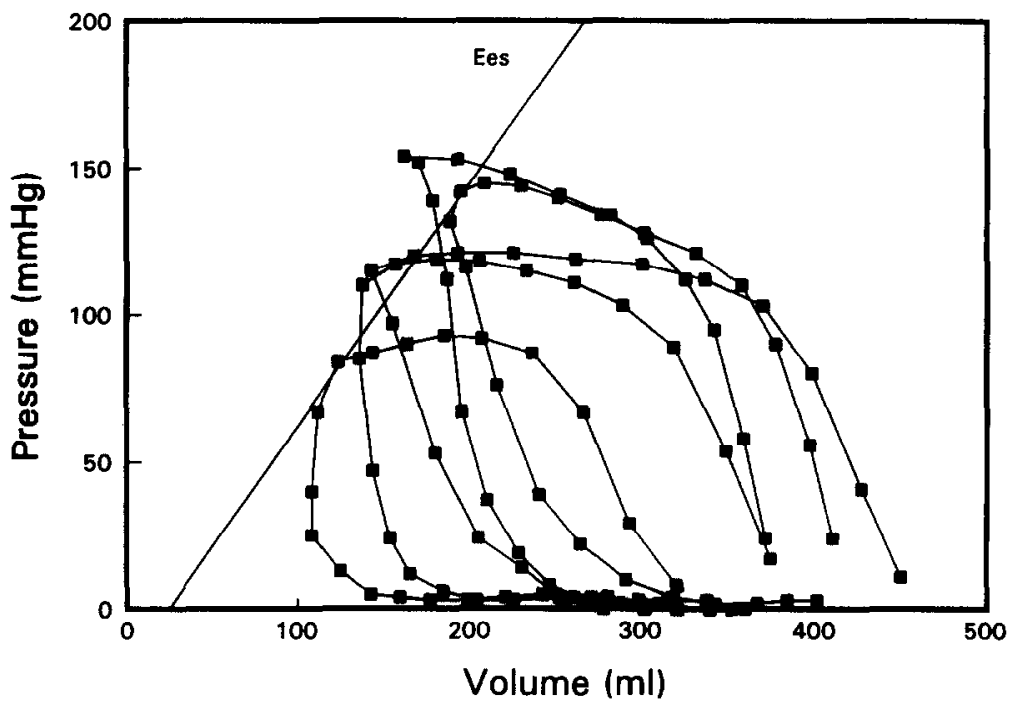

Fig. 1. Multiple pressure-volume loops from a representative patient with long-term mitral regurgitation. The maximum pressure-volume ratios from each pressure-volume loop have been subjected to linear regression analysis to obtain $\mathrm{E}_{\mathrm{es}}$, a relatively load-independent index of left ventricular contractility.

gurgitation. Another assumption in this investigation was that $\mathrm{E}_{\mathrm{a}}$ reflected total arterial load in the control subjects and in patients with long-term mitral regurgitation. Studies by Latham et al ${ }^{20}$ have demonstrated that $\mathrm{E}_{\mathrm{a}}$ detects differences in arterial load and responds similarly to the classic components of arterial load in normotensive and hypertensive nonhuman primates when these variables are affected by pharmacologic agents. Furthermore, in normotensive and hypertensive patients studied by Kelley et al., ${ }^{21} \mathrm{E}_{\mathrm{a}}$ was representative of the summed classic components of arterial load. Thus it would seem reasonable to assume that $\mathrm{E}_{\mathrm{a}}$ is reflective of total arterial load within the general theoretic framework of the left ventricular-arterial coupling relationship.

To assess left ventricular mechanical (pump) efficiency, left ventricular stroke work (SW) was obtained by calibrated planimetry of each pressure-volume loop. The result was then multiplied by 0.0136 to convert from $\mathrm{mm}$ $\mathrm{Hg} \cdot \mathrm{ml}$ to gram-meters. The left ventricular pressurevolume area was obtained by calibrated planimetry of the area enclosed by the end-systolic and diastolic curves and the systolic portion of each pressure-volume loop. ${ }^{22-25}$ The ratio of external work (SW) to pressure-volume area is reflective of left ventricular pump efficiency, that is, the efficiency of converting the total energy available to the left ventricle into external work. It is important to recognize that, although the left ventricular pressure-volume area has a linear relationship with myocardial oxygen consumption, ${ }^{23-25}$ this relationship has a variable $\mathrm{Y}$ axis offset as a result of basal metabolism and the energy costs of excitation-contraction coupling, which are not reflected in the pressure-volume area. Thus left ventricular pump efficiency as used in this investigation cannot be assumed to be synonymous with myocardial efficiency.
To obtain "effective" left ventricular stroke work-that is, forward stroke work $\left(\mathrm{SW}_{\mathrm{f}}\right)$-in the patients with longterm mitral regurgitation, total left ventricular stroke work was divided by regurgitant index to eliminate regurgitant work. To obtain left ventricular pump efficiency, regurgitant work was decremented from the total pressure-volume area so that the left ventricular pump efficiency for performing forward stroke work could be considered after eliminating regurgitant stroke work and the regurgitant portion of the pressure-volume area.

Statistical analysis. All data are expressed as the mean \pm 1 standard deviation (SD). The data were analyzed using either nonpaired $t$ tests, paired $t$ tests, or an appropriate analysis of variance where indicated. In the latter case, if a significant $F$ statistic was obtained, Dunnett's $t$ tests were used to identify differences. Significant differences were considered present when a probability of 0.05 or less was obtained.

\section{RESULTS}

Mitral regurgitation subgroups. The 26 patients with long-term mitral regurgitation were subgrouped according to their left ventricular $\mathrm{E}_{\mathrm{es}}$ values and ejection fractions. The $\mathrm{E}_{\mathrm{es}}$ values in the 22 control subjects without definable cardiac disease averaged $3.51 \pm 1.26 \mathrm{~mm} \mathrm{Hg} / \mathrm{ml}$. The lower limit of normal was defined as two standard deviations below the mean or $0.99 \mathrm{~mm} \mathrm{Hg} / \mathrm{ml}$. The patients with mitral regurgitation were therefore initially subgrouped according to whether they had normal $\mathrm{E}_{\mathrm{es}}$ values. Group I consisted of all patients with long-term mitral regurgitation who had a normal $\mathrm{E}_{\mathrm{es}}$ value. For these 11 patients with mitral regurgitation, the $E_{\mathrm{es}}$ 
Ees $(\mathrm{mmHg} / \mathrm{ml})$

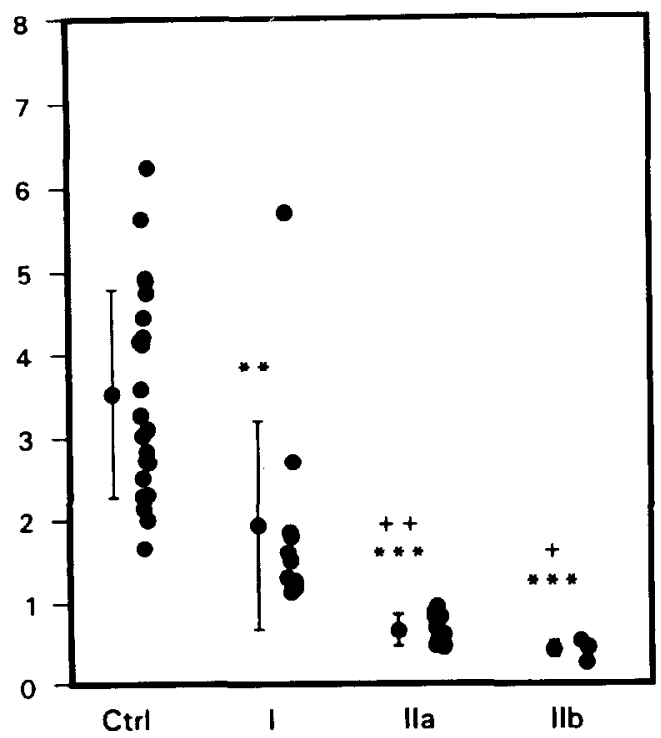

Corrected Ees $(\mathrm{mmHg} / \mathrm{ml})$

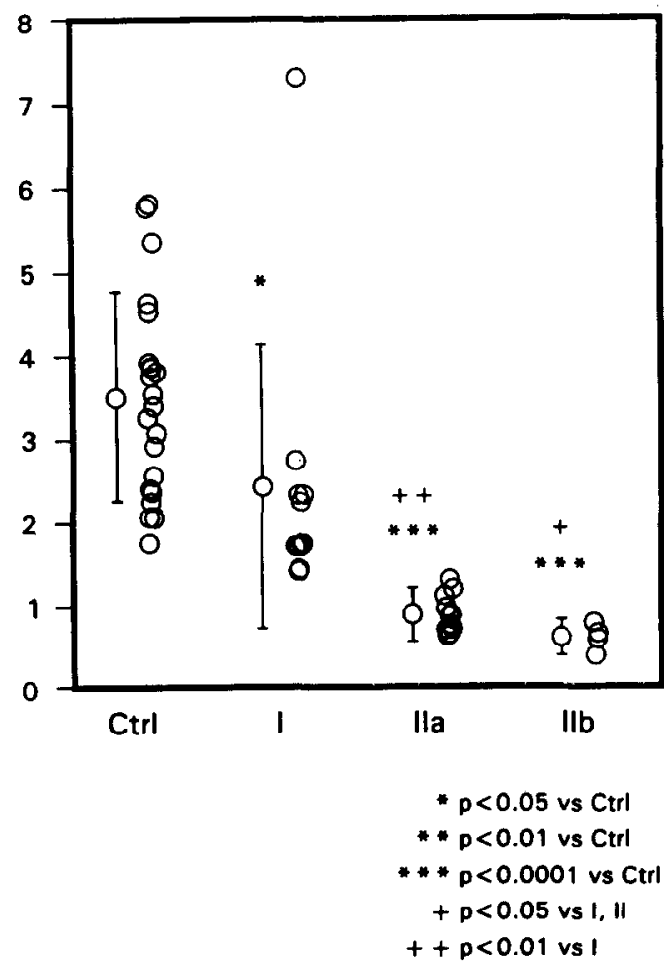

FIg. 2. Individual and mean $\mathbf{E}_{\mathrm{es}}$ values for the control subjects (Ctrl), patients with long-term mitral regurgitation and normal $\mathrm{E}_{\mathrm{es}}$ (group I), those with impaired $\mathrm{E}_{\mathrm{es}}$ but normal left ventricular ejection fractions (group IIa), and those with impaired $\mathrm{E}_{\mathrm{es}}$ and impaired left ventricular ejection fractions (group IIb). Differences in mean values are noted.

values averaged $1.92 \pm 1.32 \mathrm{~mm} \mathrm{Hg} / \mathrm{ml}$. These patients had an average left ventricular end-diastolic volume of $216 \pm 7 \mathrm{ml}$, an end-systolic volume of $86 \pm 34 \mathrm{ml}$, and an ejection fraction of $0.60 \pm 0.09$.

Group II patients with long-term mitral regurgitation by definition had reduced $\mathrm{E}_{\mathrm{es}}$ values of less than $0.99 \mathrm{~mm} \mathrm{Hg} / \mathrm{ml}$. This group was further divided into groups IIa and IIb. For the 11 patients with mitral regurgitation in group $\mathrm{IIa}$, the $\mathrm{E}_{\mathrm{es}}$ values averaged $0.66 \pm 0.17 \mathrm{~mm} \mathrm{Hg} / \mathrm{ml}$. These patients with mitral regurgitation had an average left ventricular enddiastolic volume of $264 \pm 58 \mathrm{ml}$ and an end-systolic volume of $113 \pm 34 \mathrm{ml}$, and their left ventricular ejection fractions were normal, averaging $0.57 \pm$ 0.08 .

The remaining four palients with mitral regurgitation were in group IIb. These patients had reduced $\mathrm{E}_{\mathrm{es}}$ values that averaged $0.42 \pm 0.10 \mathrm{~mm} \mathrm{Hg} / \mathrm{ml}$, and they had reduced left ventricular ejection fractions. They had an average left ventricular end-diastolic volume of $315 \pm 40 \mathrm{ml}$, an end-systolic volume of $186 \pm 44 \mathrm{ml}$, and an ejection fraction of $0.42 \pm 0.10$.
Therefore patients with long-term mitral regurgitation in groups Ila and IIb had progressively greater impairment of left ventricular contractile function, presumably mild in group IIa and severe in group IIb. Further, the left ventricular regurgitant indices in these patients were similar, averaging $2.23 \pm 0.81$ in group I, $2.62 \pm 0.89$ in group IIa, and $2.82 \pm 1.14$ in group IIb.

Despite normal individual $\mathrm{E}_{\mathrm{es}}$ values in the group I mitral regurgitation patients, the average $E_{\mathrm{es}}$ in this subgroup of patients differed from that in the control subjects $(p<0.01)$. Even following a correction for differences in heart size, the average $\mathrm{E}_{\text {es }}$ for the group I mitral regurgitation patients remained less than that in the control subjects $(p<0.05)$. This suggests that although these patients had normal individual left ventricular chamber elastance values, they were clustered in the low normal $\mathrm{E}_{\mathrm{es}}$ range (Fig. 2). By definition, the average $\mathrm{E}_{\mathrm{es}}$ values in the group IIa and $\mathrm{IIb}$ patients with long-term mitral regurgitation were reduced compared with those in the control subjects ( $p<0.0001$ for both comparisons). 

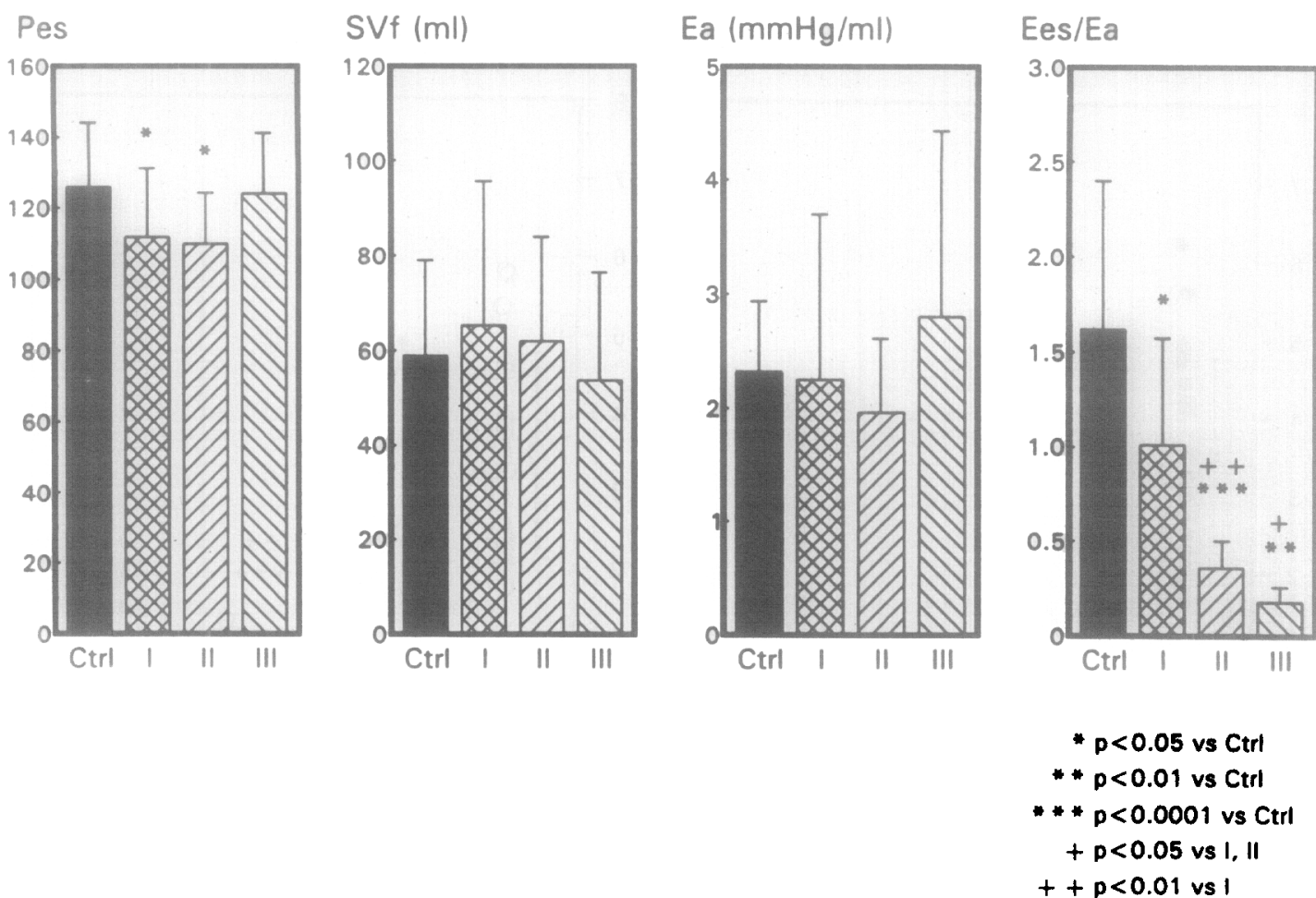

Fig. 3. Average values for end-systolic pressure $\left(P_{e s}\right)$, forward left ventricular stroke volume $\left(S V_{f}\right)$, effective arterial elastance $\left(E_{\alpha}\right)$, and left ventricular-arterial coupling $\left(E_{e s} / E_{a}\right)$ are shown for control subjects and the three subgroups of patients with long-term mitral regurgitation. Significant differences are noled.

Left ventricular-arterial coupling. As shown in Fig. 3 , left ventricular arterial coupling varied in the patients with mitral regurgitation. Left ventricular end-systolic pressure, $\mathrm{P}_{\mathrm{es}}$, was decreased in groups $\mathrm{I}$ and IIa (112 \pm 19 and $110 \pm 14 \mathrm{~mm} \mathrm{Hg}, p<0.05$ for both) compared with that in the control subjects $(126 \pm 18 \mathrm{~mm} \mathrm{Hg})$. The $\mathrm{P}_{\mathrm{es}}$ in group IIb patients with long-term mitral regurgitation of $124 \pm 17 \mathrm{~mm} \mathrm{Hg}$ did not differ from that in the control patients. Forward left ventricular stroke volume, $\mathbf{S V}_{f}$, was similar in all four patient groups, averaging $59 \pm 20 \mathrm{ml}$ in the control subjects and $65 \pm 30,62 \pm 22$, and $54 \pm 23$ $\mathrm{ml}$ in the group I, IIa, and IIb patients with long-term mitral regurgitation, respectively. Consequently, effective arterial elastance, $E_{a}$, varied little between patient groups. In the control subjects, $\mathrm{E}_{\mathrm{a}}$ averaged $2.32 \pm 0.61 \mathrm{~mm} \mathrm{Hg} / \mathrm{ml}$, and it was similar in the group I mitral regurgitation patients, averaging 2.25 $\pm 1.45 \mathrm{~mm} \mathrm{Hg} / \mathrm{ml}$. It was slightly reduced in the group IIa mitral regurgitation patients at $1.96 \pm 0.65$ $\mathrm{mm} \mathrm{Hg} / \mathrm{ml}$, and it was slightly increased in the group IIb mitral regurgitation patients at $2.80 \pm 1.63 \mathrm{~mm}$ $\mathrm{Hg} / \mathrm{ml}$. However, none of these values differed significantly.

In contrast, there was progressive deterioration in left ventricular-arterial coupling, $\mathrm{E}_{\mathrm{es}} / \mathrm{E}_{\mathrm{a}}$, between patient groups. In the control subjects, $\mathrm{E}_{\mathrm{es}} / \mathrm{E}_{\mathrm{a}}$ averaged $1.62 \pm 0.78$, and there was a progressive decrease in this ratio in the patients with long-term mitral regurgitation, to $1.01 \pm 0.56$ in group $\mathrm{I}(p<0.05$ vs control), $0.36 \pm 0.14$ in group IIa $(p<0.0001$ vs control and $p<0.01$ vs group I), and to $0.18 \pm 0.08$ in group IIb ( $p<0.01$ vs control and $p<0.05$ vs group I and IIa). It is apparent that since $\mathrm{E}_{\mathrm{a}}$ varied little between the four patient groups, the left ventricular-arterial coupling ratios were strongly influenced by the $\mathrm{E}_{\mathrm{es}}$ values.

The effects of these differences in left ventriculararterial coupling on forward and total stroke work and their corresponding pump efficiency values are shown in Fig. 4. Forward stroke work, $\mathrm{SW}_{\mathrm{f}}$, did not differed between the four groups of patients. It averaged $76 \pm 31$ gram-meters in the control subjects, and it averaged $71 \pm 31,69 \pm 24$, and $58 \pm 34$ grammeters in the group I, IIa, and IIb patients with longterm mitral regurgitation, respectively. Total left ventricular stroke work, $\mathrm{SW}_{\mathrm{t}}$, was significantly increased in all subgroups of patients with long-term mitral regurgitation. Total left ventricular stroke work in the patients with long-term mitral regurgitation averaged $143 \pm 54$ gram-meters in group I ( $p<0.0001$ vs control), $168 \pm 41$ gram-meters in 

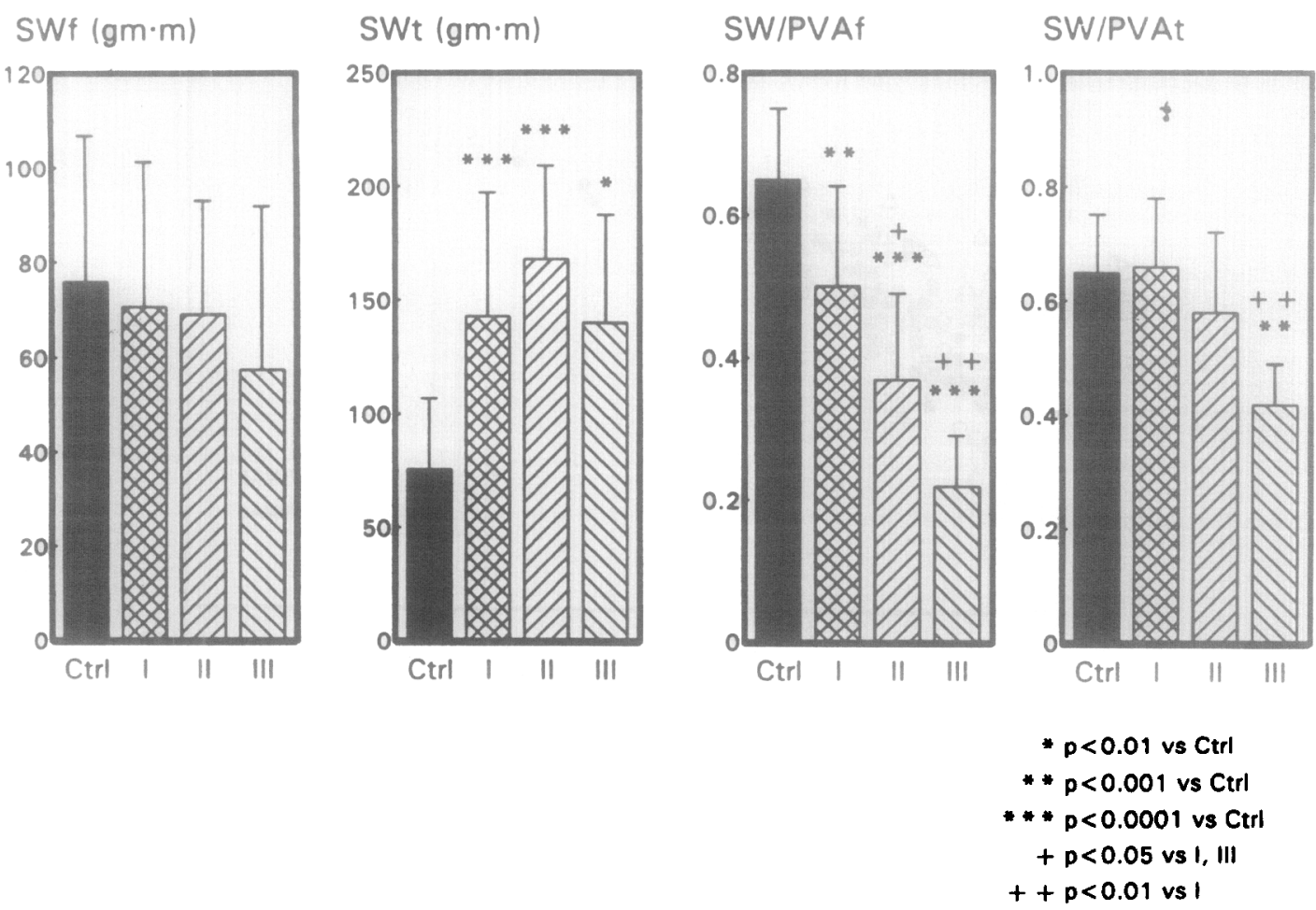

Fig. 4. Average values for forward left ventricular stroke work $\left(S W_{f}\right)$, total left ventricular stroke work $\left(S W_{t}\right)$, forward left ventricular pump efficiency $\left(S W / P V A_{f}\right)$, and total left ventricular pump efficiency $\left(S W / P V A_{t}\right)$ are shown for control subjects and the three subgroups of patients with long-term mitral regurgitation, in a format similar to that of the previous figure. Significant differences are noted.

group IIa ( $p<0.0001$ vs control), and $140 \pm 47$ gram-meters in group IIb ( $p<0.01$ vs control). There was no significant difference in total stroke work between the three subgroups of patients with long-term mitral regurgitation.

The pump efficiency of performing forward stroke work demonstrated a progressive reduction in the patients with mitral regurgitation from the control group value of $0.65 \pm 0.10$. In the group I patients with long-term mitral regurgitation, $\mathrm{SW} / \mathrm{PVA}_{\mathrm{f}}$ average $0.50 \pm 0.14$ ( $p<0.001$ vs control); it averaged $0.37 \pm 0.12$ in group IIa $(p<0.0001$ vs control and $p<0.05$ vs group I). SW/PVA $\mathrm{f}_{\mathrm{f}}$ averaged $0.22 \pm 0.07$ in group IIb ( $p<0.0001$ vs control, $p<0.01$ vs group $\mathrm{I}$, and $p<0.05$ vs group IIa). In contrast, the pump efficiency of performing total stroke work, SW/PVA was similar for control subjects $(0.65 \pm 0.10)$ and for patients with normal or mildly impaired left ventricular contractile function, where it averaged $0.66 \pm$ 0.12 and $0.58 \pm 0.14$, respectively. The pump effciency of performing total left ventricular stroke work deteriorated only in the patients with mitral regurgitation who had severe left ventricular contractile dysfunction (group IIb), where it averaged $0.42 \pm 0.07$ ( $p<0.001$ vs control and $p<0.01$ vs group I). Thus while left ventricular SW/PVA $t$ was preserved until severe left ventricular contractile dysfunction occurred, the pump efficiency of performing forward stroke work, SW/PVA strated progressive deterioration in patients with long-term mitral regurgitation in comparison to the control patients despite preservation of normal left ventricular $\mathrm{SW}_{\mathrm{f}}$ at rest.

The relationship between left ventricular pump efficiency and left ventricular-arterial coupling is shown in Fig. 5. This figure illustrates the relationship in the control subjects over a wide range of left ventricular load and the relationship in the patients with long-term mitral regurgitation for forward stroke work and total stroke work under basal conditions. The strong curvilinear relationship for the control subjects is continued in the patients with mitral regurgitation for forward stroke work. In contrast, the relationship for total stroke work in the patients with mitral regurgitation is displaced upward for any given left ventricular-arterial coupling ratio. This demonstrates that the relationship between left ventricular pump efficiency for performing forward stroke work and left ventricular-arterial coupling in those patients with mitral regurgitation is on a con- 


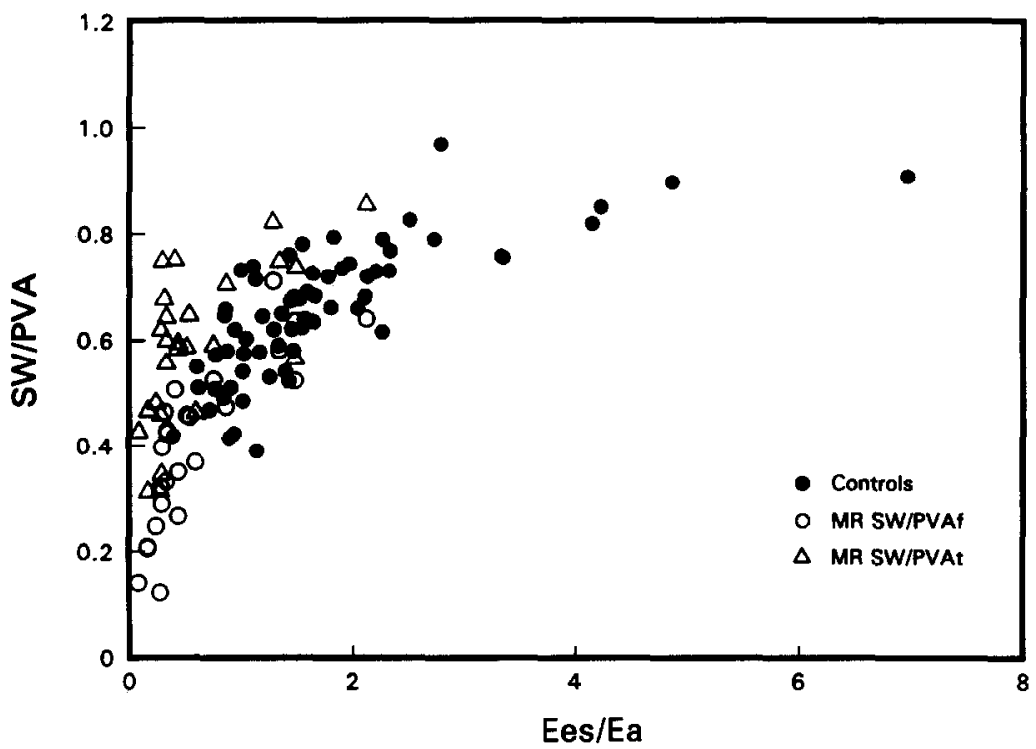

Fig. 5. Individual values for forward left ventricular pump efficiency (SW/PVAf) and total left ventricular pump efficiency (SW/PVA $)$ are plotted against their corresponding left ventricular-arterial coupling ratios $\left(E_{e s} / E_{\alpha}\right)$ for patients with long-term mitral regurgitation during baseline hemodynamic conditions and for the control subjects over a wide range of loading condilions. Note the relationship is curvilinear and that pump efficiency for performing forward left ventricular stroke work in patients with long-term mitral regurgitation is on a continuum with that in control subjects. In contrast, the pump efficiency of performing total left ventricular stroke work is superiorly and leftwardly displaced off this continuum. This suggests that the pump efficiency of performing total left ventricular stroke work is maintained despite an impaired left ventricular-arterial coupling ratio, while the pump efficiency of performing forward left ventricular stroke work is impaired and falls low on the continuum because of impaired contractile function.

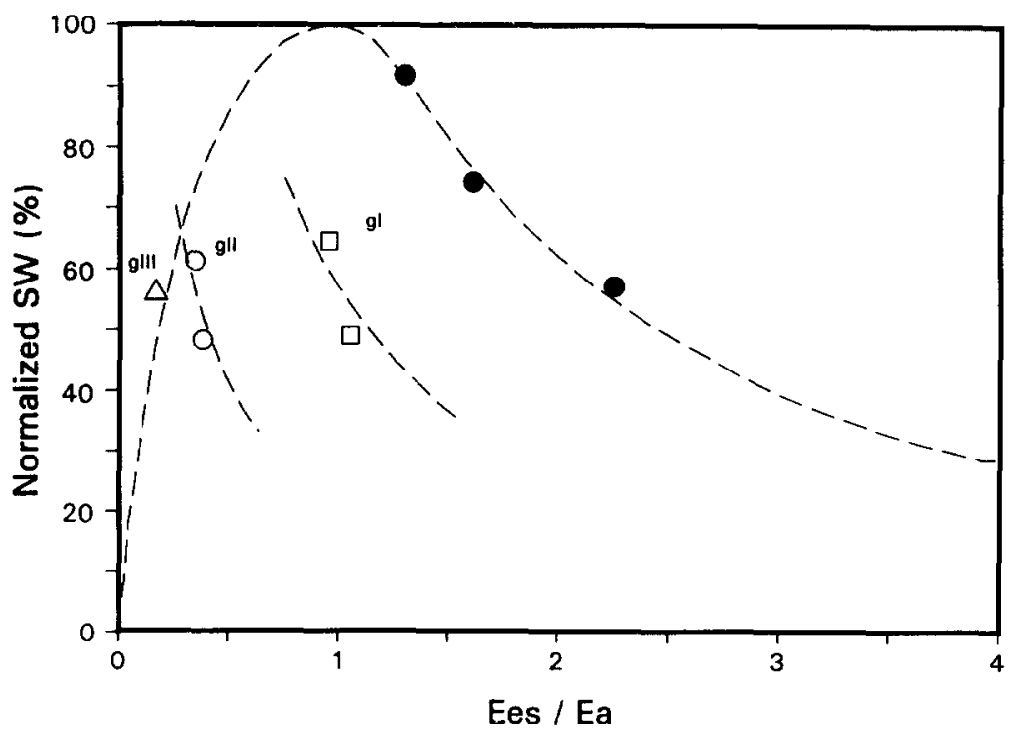

Fig. 6. Plot of normalized forward left ventricular stroke work (on the ordinate) versus the left ventricular-arterial coupling ratio $\left(E_{e s} / E_{\alpha}\right)$ (on the abscissa). Theoretic maximal left ventricular stroke work occurs in a normal heart at an $\mathrm{E}_{\mathrm{es}} / \mathrm{E}_{\mathrm{a}}$ ratio of 1.0. This value was set in control subjects to $100 \%$ and then all values were normalized to this theoretic maxima. Note for the control subjects that over a wide range of loading conditions they fall on this theoretic continuum. Importantly, for each subgroup of patients with long-term mitral regurgitation, there was progressive inferior and leftward displacement of this relationship as contractile function deteriorated. 

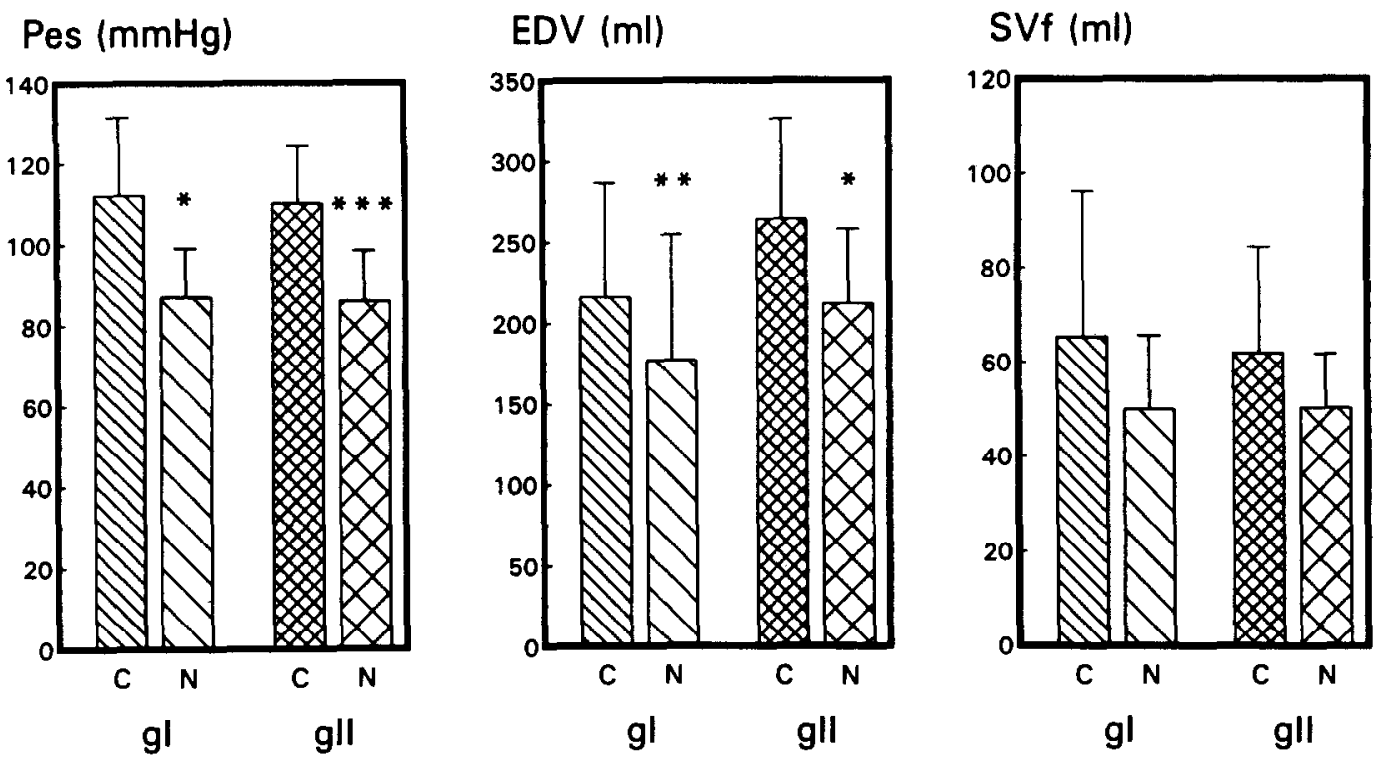

$$
\begin{aligned}
& C=\text { Control } \\
& N=\text { Nitroprusside }
\end{aligned}
$$

$$
\begin{aligned}
* p & <0.01 \text { vs } C \\
* * p & <0.001 \text { vs C } \\
* * p & <0.0001 \text { vs C }
\end{aligned}
$$

Fig. 7. Effects of maximal vasodilation on end-systolic pressure $\left(P_{e s}\right)$, left ventricular end-diastolic volume $(E D V)$, and left ventricular forward stroke work $\left(S V_{f}\right)$, in two subgroups of patients with long-term mitral regurgitation (group I and IIa). The number of patients within each of these two subgroups of mitral regurgitation patients were adequate to perform these analyses; however, there were too few patients to do so in subgroup IIb. Significant differences are noted.

tinuum with that in the control subjects, while the left ventricular pump efficiency for performing total stroke work is maintained and displaced upward off this continuum, despite impaired left ventriculararterial coupling. This suggests that the low energy cost of performing regurgitant stroke work caused by the low impedance left atrium obscures an impairment in left ventricular pump efficiency for performing forward stroke work.

The relationship between normalized left ventricular stroke work and left ventricular-arterial coupling is demonstrated in Fig. 6 for the control subjects and for the patients with long-term mitral regurgitation. The dashed line represents the theoretic relationship between normalized stroke work and left ventricular-arterial coupling in a normal heart. Maximum left ventricular stroke work would therefore occur when left ventricular chamber elastance and effective arterial elastance are optimally coupled at an $\mathrm{E}_{\mathrm{es}} / \mathrm{E}_{\mathrm{u}}$ ratio of 1.0. The normalized stroke work values in the control subjects fall on this theoretic relationship over a wide range of loading conditions. In contrast, the group I mitral regurgitation patients, who had an $\mathrm{E}_{\mathrm{es}} / \mathrm{E}_{\mathrm{a}}$ ratio of approx- imately 1.0, demonstrated impaired normalized forward stroke work for this coupling ratio in comparison to that predicted for the control subjects $(p<0.001)$. The group IIa and IIb patients with long-term mitral regurgitation fall on the downslope of this theoretic relationship, consistent with their impaired left ventricular contractile function.

Effects of vasodilation on left ventricular-arterial coupling. The effects of systemic arterial vasodilation on left ventricular-arterial coupling are demonstrated in Figs. 7 and 8. As shown in Fig. 7, the amount of vasodilation in patients with long-term mitral regurgitation and normal contractile function (group I) was comparable to that in patients with mildly impaired contractile function (group IIa). Left ventricular end-systolic pressure, $\mathrm{P}_{\mathrm{es}}$ decreased in group I from $112 \pm 19$ to $87 \pm 12 \mathrm{~mm} \mathrm{Hg}(p<0.01)$. Similarly, in group IIa, $\mathrm{P}_{\mathrm{es}}$ decreased from $110 \perp 14$ to $86 \pm 12 \mathrm{~mm} \mathrm{Hg}(p<0.0001)$. There was also a decrease in left ventricular end-diastolic volume, EDV, from $216 \pm 72$ to $177 \pm 77 \mathrm{ml}(p<0.001)$ in group I and from $264 \pm 61$ to $212+46 \mathrm{mls}(p<0.01)$ in group IIa. Although forward left ventricular stroke volume fell in both subgroups, this change was sim- 

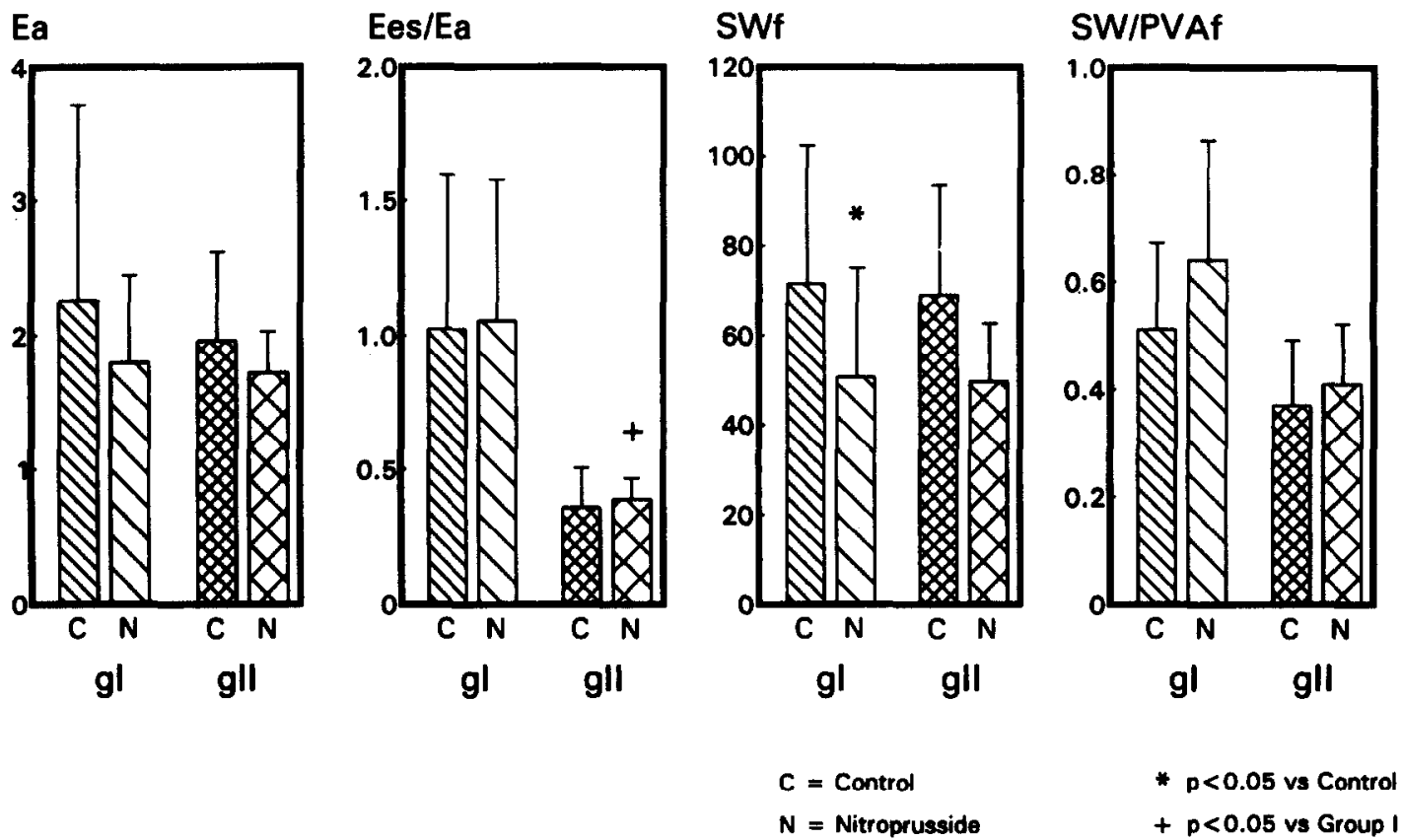

Fig. 8. In a format similar to that of Fig. 7, the effects of maximal vasodilation on effective arterial elastance $\left(E_{a}\right)$, left ventricular-arterial coupling $\left(E_{e s} / E_{a}\right)$, forward left ventricular stroke work $\left(S W_{f}\right)$, and pump efficiency of performing forward left ventricular stroke work $\left(S W / P V A_{f}\right)$ are shown. Significant differences are noted. Note that consistent with the theoretic predictions, vasodilation caused a modest change in $\mathrm{E}_{\mathrm{es}} / \mathrm{E}_{\mathrm{a}}$ and a decrease in $\mathrm{SW}_{\mathrm{f}}$ commensurate with an increase in SW/PVA. Thus using these data and the baseline hemodynamic data, a series of curves relating normalized forward left ventricular stroke work to their corresponding $\mathrm{E}_{\mathrm{es}} / \mathrm{E}_{\mathrm{a}}$ ratios were generated (Fig. 6) for these two subgroups of patients with long-term mitral regurgitation.

ilar. In group I it decreased from $65 \pm 30$ to $50 \pm 15$ $\mathrm{ml}$, and in group IIa it decreased from $62 \pm 22$ to $50 \pm 11 \mathrm{ml}$.

Because of the comparable changes in $\mathrm{P}_{\mathrm{es}}$ and $\mathrm{SV}_{\mathrm{f}}$, effective arterial elastance, $\mathrm{E}_{\mathrm{a}}$, was only mildly affected by vasodilation. The average $\mathrm{E}_{\mathrm{a}}$ decreased from $2.25 \pm 1.45$ to $1.79 \pm 0.64 \mathrm{~mm} \mathrm{Hg} / \mathrm{ml}$ in group I, and it decreased from $1.96 \pm 0.65$ to $1.70 \pm 0.30$ $\mathrm{mm} \mathrm{Hg} / \mathrm{ml}$ in group IIa. The left ventricular-arterial coupling ratio, $\mathrm{E}_{\mathrm{es}} / \mathrm{E}_{\mathrm{a}}$, was also little affected by vasodilation. It was $1.02 \pm 0.57$ before vasodilation and during maximal vasodilation it was $1.05 \pm 0.52$ in group I. Similarly, in group IIa, it was $0.36 \pm 0.14$ before vasodilation and during maximal vasodilation it was $0.39 \pm 0.07$.

Forward left ventricular stroke work, $\mathrm{SW}_{\mathrm{f}}$, decreased in both groups. It decreased from $71 \pm 31$ to $51 \pm 24$ gram-meters $(p<0.05)$ in group I, and it decreased from $69 \pm 24$ to $50 \pm 13$ gram-meters in group IIa. The pump efficiency of performing forward left ventricular stroke work, SW/PVA, increased slightly in both groups, from $0.51 \pm 0.16$ to $0.64 \pm$ 0.22 in group $I$ and from $0.37 \pm 0.12$ to $0.41 \pm 0.11$ in group IIa.
To further illustrate the effects of vasodilation on forward left ventricular stroke work and left ventricular-arterial coupling, forward left ventricular stroke work was normalized to the theoretic maximal at an $\mathrm{E}_{\mathrm{es}} / \mathrm{E}_{\mathrm{a}}$ of 1.0 in the control subjects and these data are incorporated into Fig. 6 . The effects of vasodilation on normalized forward left ventricular stroke work were plotted against the left ventricular-arterial coupling ratio to demonstrate that new relationships between these variables existed in these two subgroups of patients with long-term mitral regurgitation. The downward and leftward displaced relationships between normalized forward left ventricular stroke work and left ventricular-arterial coupling for these two subgroups of patients with long-term mitral regurgitation (group I and IIa) in comparison to that in the control subjects indicate impaired left ventricular pump function for their corresponding $\mathrm{E}_{\mathrm{es}} / \mathrm{E}_{\mathrm{a}}$ ratios.

\section{DISCUSSION}

Understanding left ventricular pump function in patients with long-term mitral regurgitation is difficult because of the confounding influence of the low 
impedance left atrium. Outwardly, left ventricular pump function appears normal, despite left ventricular dilation, until late in the hemodynamic course when irreversible myocardial dysfunction supervenes. ${ }^{26}$ Left ventricular pump function, measured routinely as left ventricular ejection fraction or fractional shortening, remains normal because end-systolic load on the left ventricle is normal and end ejection uncouples from end systole. ${ }^{2,3}$ There are, however, several observations that suggest that left ventricular pump function may not be entirely adequate in patients with long-term mitral regurgitation. There is evidence to suggest that left ventricular hypertrophy for the degree of left ventricular dilation may not be sufficient in this valve lesion because of an increase in the left ventricular radius: thickness ratio. ${ }^{3}$ Furthermore, left ventricular dilation causes a change in left ventricular shape to a more globular configuration. No studies, however, are available that have examined this complex issue in a sophisticated manner to answer the question of whether left ventricular pump function is adequate in this setting. The limitations have mainly been the problem of separating forward from regurgitant output and the absence of a suitable theoretic framework within which this issue might be examined.

The left ventricular-arterial coupling concept proposed by Sunagawa et al. ${ }^{6,7,27}$ provides a convenient theoretic framework within which left ventricular pump function can be evaluated through the interaction of the left ventricle with the arterial system. If the contribution of the low impedance left atrium to overall left ventricular pump function can be eliminated (which can be accomplished with radionuclide angiography), an appreciation of forward left ventricular pump function in patients with long-term mitral regurgitation can be examined and compared with that in control subjects without evidence of cardiac pathology. Since both the left ventricle and arterial system operate in the pressure-volume plane, the transfer of energy from the left ventricle to the arterial system, that is, the performance of external work, is maximal when these two elastances are equal. ${ }^{27,28}$ Thus by standardizing left ventricular output to the maximal theoretic value predicted for normal human hearts, the effects of long-term mitral regurgitation on forward left ventricular work and pump efficiency can be examined over a range of contractile states and coupling ratios.

The hypothesis tested in this investigation was that the additional contribution of the low impedance left atrium to left ventricular ejection obscures left ventricular pump dysfunction in patients with long-term mitral regurgitation. Left ventricular pump dysfunction would be manifest, therefore, by either impaired left ventricular-arterial coupling, impaired left ventricular stroke work for any left ventricle-arterial coupling ratio, impaired efficiency of energy transfer from the left ventricle to the arterial system, or by a combination of these observations. Data from this investigation demonstrate that over a range of left ventricular contractile states left ventricular-arterial coupling is abnormal in patients with long-term mitral regurgitation. The amount of energy transferred from the left ventricle to the arterial system is normal under resting conditions but less than would be predicted for a normal heart at a comparable coupling ratio. Left ventricular pump efficiency for performing forward left ventricular stroke work is also impaired. An additional observation from these data is that in spite of impaired left ventricular-arterial coupling, the pump efficiency of performing total left ventricular stroke work was not impaired. These data suggest that the efficiency of performing regurgitant volume work obscures left ventricular pump dysfunction in patients with longterm mitral regurgitation.

The data from this investigation also demonstrate that vasodilation has little effect on left ventricular pump dysfunction when examined within the theoretic framework of the left ventricular-arterial coupling relationship. Over the full range of left ventricular contractile states, vasodilation demonstrated modest reductions in effective arterial elastance and increases in left ventricular-arterial coupling. Associated with this increase in left ventricular-arterial coupling was a decrease in left ventricular forward stroke work. Although forward left ventricular stroke work fell, the pump efficiency of performing forward stroke work improved. Importantly, for any given left ventricular contractile state, vasodilation helped to generate a series of relationships between normalized forward left ventricular stroke work and left ventricular-arterial coupling. These relation demonstrated that a series of inferiorly and leftwardly displaced curves existed in comparison to those in control subjects. The displacement of these curves was progressive and depended upon the degree of left ventricular contractile impairment. Thus the impairment of left ventricular-arterial coupling and pump efficiency appears to be related to a progressive deterioration in contractile function.

It is important to appreciate that basic animal models of long-term mitral regurgitation have provided data that are consistent with our observation of a progressive deterioration in left ventricular contractile state in patients with long-term mitral regurgitation. Nakano et al. ${ }^{4}$ have shown, in chronically 
instrumented dogs in whom mitral regurgitation was created, that several indices of left ventricular contractile state progressively deteriorated. Importantly, the reduction in left ventricular contractile state is reversible with correction of the valve lesion. This observation has been confirmed in other studies from this laboratory. ${ }^{29}$ Thus this animal model of chronic mitral regurgitation has documented the same progressive deterioration in left ventricular contractile state that was observed in the patients with longterm mitral regurgitation in this investigation.

There are two potential limitations that should be considered. First, the use of left ventricular chamber elastance in patients with left ventricular volume overload might be questioned because of the relationship between $\mathrm{E}_{\mathrm{es}}$ and heart size. ${ }^{30}$ There are four observations that suggest that $\mathrm{E}_{\mathrm{eg}}$ is valuable in assessing left ventricular contractile state in patients with left ventricular volume overload. They include the observation in this investigation that, following a correction for heart size, there was no significant alteration in the data or therefore in the conclusions drawn from the data. Further, left ventricular chamber elastance has been demonstrated to identify subgroups of patients with long-term mitral regurgitation in whom the temporal changes in left ventricular size and ejection fraction differ following correction of left ventricular volume overload. ${ }^{5}$ Moreover, left ventricular end-diastolic and end-systolic volumes did not discriminate between these long-term responses to mitral valve surgery in patients with long-term mitral regurgitation. Additionally, data in animal studies show that $\mathrm{E}_{\mathrm{es}}$ and other indices of left ventricular contractile state change comparably and in a directionally similar manner after development of chronic mitral regurgitation., $29 \mathrm{E}_{\mathrm{cs}}$ detects changes in left ventricular contractile state similar to changes in end-systolic stiffness, which have been shown to correspond to in vitro changes in myocyte force generation, suggesting that these indices are probably detecting true changes in myocyte contractile properties. ${ }^{29,31,32}$ Finally, in patients studied after successful valve surgery for long-term mitral regurgitation, there is improvement in left ventricular contractility. 33,34 This is consistent with the animal data. $^{4,29}$ Thus it seems reasonable to infer that changes in left ventricular contractility are being detected by $\mathrm{E}_{\mathrm{es}}$ in these patients.

Second, the use of the radionuclide left ventricular regurgitant index to partition total left ventricular stroke output into forward and regurgitant stroke volume and work represented a novel approach to generating $E_{a}$ and forward pump efficiency. It was observed that, following this division into forward and regurgitant stroke volume and work, the average forward left ventricular stroke volume was equivalent to that in the control subjects, as was the forward left ventricular stroke work. Despite preservation of resting forward stroke volume and stroke work, the left ventricle was mechanically inefficient at performing this work. Although it is difficult to partition total left ventricular stroke volume and work into their specific forward and regurgitant portions, this approach provided a reasonable approximation. This was evident when the pump efficiency of the left ventricle was plotted against left ventricular-arterial coupling. The pump efficiency of performing forward left ventricular stroke work fell on a continuum with that for the control subjects over a wide range of left ventricular load, while the pump efficiency of performing total left ventricular stroke work was displaced upward and to the left for any given left ventricular-arterial coupling ratio. This further suggests that the partitioning of total left ventricular stroke work into its approximate forward and regurgitant fractions and the calculation of forward left ventricular pump efficiency were probably reflective of the proportionate work being performed into the arterial system and left atrium.

In conclusion, the data in this investigation indicate that, despite the outward evidence for normal left ventricular pump function in patients with longterm mitral regurgitation when conventional approaches are used, a progressive deterioration in left ventricular contractile state leads to an impairment of left ventricular-arterial coupling and pump efficiency in these patients. Consequently, once the left ventricle begins to dilate in patients with long-term mitral regurgitation, progressive deterioration in left ventricular-arterial coupling and pump efficiency begins, suggesting that an earlier consideration of mitral valve surgery in this valve lesion may be warranted to preserve left ventricular contractile function and to restore pump efficiency toward normal.

We thank Daniel G. Montgomery, BS, and Kimberly Arment for their assistance in preparation of the manuscript.

\section{REFERENCES}

1. Wisenbaugh 'I', Spann JF, Carabello BA. Differences in myocardial performance and load between patients with similar amounts of chronic aortic versus chronic mitral regurgitation. J Am Coll Cardiol 1984;3:916-23.

2. Brickner ME, Starling MR. Dissociation of end-systole from end-ejection in patients with long-term mitral regurgitation. Circulation 1990;81:1277-86.

3. Schuler G, Peterson KL, Johnson A, Francis G, Dennish G, Utley J, Daily, PO, Ashburn W, Ross .T. Temporal response of left ventricular performance to mitral valve surgery. Circulation 1979;6:1218-31.

4. Nakano K, Swindle MM, Spinale F, Ishihara K, Kanazawa S, Smith A, Biederman RWW, Clamp L, Hamada Y, Zile MR, 
Carabello BA. Depressed contractile function due to canine mitral regurgitation improves after correction of the volume overload. J Clin Invest 1991;87:2077-86.

5. Starling MR, Kirsh MM, Montgomery DG, Gross MD. Impaired left ventricular contractile function in patients with long-term mitral regurgitation and a normal ejection fraction. J Am Coll Cardiol 1993;22:239-50.

6. Sunagawa K, Maughan WL, Burkhoff D, Sagawa K. Left ventricular interaction with arterial load studied in isolated canine ventricle. Am J Physiol 1983;245:H773-80.

7. Burkhoff D, Sagawa K. Ventricular efficiency predicted by an analytical model. Am J Physiol 1986;250:R1021-7.

8. Starling MR. Left ventricular-vascular coupling relations in the normal human heart. AM HEART J 1993;125:1659-66.

9. Starling MR, Walsh RA, Dell'Italia LJ, Mancini GBJ, Lasher $\mathrm{JC}$, Lancaster JL. The relationship of various measures of cnd-systole to left ventricular maximum time-varying elastance in man. Circulation 1987;76:32-43.

10. Starling MR, Montgomery DG, Mancini GBJ, Walsh RA. Load independence of the rate of isovolumic relaxation in man. Circulation 1987;76:1274-81.

11. Starling MR, Dell'Italia LJ, Walsh RA, Little WC, Benedetto AR, Nusynowitz ML. Accurate estimates of absolute left ventricular volumes from equilibrium radionuclide angiographic count data using a simple geometric attenuation correction. $\mathrm{J}$ Am Coll Cardiol 1984;3:789-98.

12. Starling MR, Dell'Italia Lu, Nusynowitz ML, Walsh RA, Little WC, Benedetto AR. Estimates of left ventricular volumes by equilibrium radionuclide angiography: importance of attenuation correction. J Nucl Med 1984;25:14-20.

13. Starling MR, Gross MD, Walsh RA, Dell'Italia LJ, Montgomery DG, Squicciarini SA, Blumhardt R. Assessment of the radionuclide angiographic left ventricular maximum time-varying elastance calculation in man. J Nucl Med 1988;29:1368-81.

14. Suga H, Sagawa K. Instantaneous pressure-volume relationships and their ratio in the excised, supported canine left ventricle. Circ Res 1974;35:117-26.

15. Sagawa K. The ventricular pressure-volume diagram revisited. Circ Res 1978;43:677-87.

16. Little WC, Cheng CP, Mumma M, Igarashi Y, VintenJohansen J, Johnston WE. Comparison of measures of left ventricular contractile performance derived from pressurevolume loops in conscious dogs. Circulation 1989;80:1378-87.

17. Starling MR. Responsiveness of the maximum time-varying elastance to alterations in left ventricular contractile state in man. AM HEART J 1989;118:1266-76.

18. Maddahi J, Berman DS, Matsuoka DT, Waxman AD, Stankus $\mathrm{KE}$, Forrester JS, Swan HJC. A new technique for assessing right ventricular ejection fraction using rapid multiple-gated equilibrium cardiac blood pool scintigraphy. Circulation 1979; 60:581-9.

19. Sorensen SG, O'Rourke RA, Chaudhuri TK. Noninvasive quantitation of valvular regurgitation by gated equilibrium radionuclide angiography. Circulation 1980;62:1089-98.
20. Latham RD, Rubal BJ, Sipkema P, Westerhof N, Virmani R, Robinowitz M, Walsh RA. Ventricular/vascular coupling and regional arterial dynamics in the chronically hypertensive baboon: correlation with cardiovascular structural adaptation. Circ Res 1988;63:798-811.

21. Kelley RP, Ting CT, Yang TM, Liu CP, Maughan WL, Chang MS, Kass DA. Effective arterial elastance as index of arterial vascular load in humans. Circulation 1992;86:513-21.

22. Suga H. Total mechanical energy of a ventricle model and cardiac oxygen consumption. Am J Physiol 1979;236:H498505.

23. Suga H, Hayashi 'T, Shirahata M. Ventricular systolic pressure-volume area as predictor of cardiac oxygen consumption. Am J Physiol 1981;240:H30-44.

24. Suga H, Hayashi T, Shirahata $M$, Suehire $S$, Hisano $R$ Regression of cardiac oxygen consumption of ventricular pressure-volume area in dog. Am J Physiol 1981;240:H320-5

25. Starling MR, Mancini GBJ, Montgomery DG, Gross MD. Relation between maximum time-varying elastance pressurevolume areas and myocardial oxygen consumption in dogs. Circulation 1991;83:304-14.

26. Ross J. Left ventricular function and the timing of surgical treatment in valvular heart disease. Ann Intern Med 1981; 94:498-504.

27. Sunagawa K, Maughan WL, Sagawa K. Optimal arterial resistance for the maximal stroke work studied in isolated canine left ventricle. Circ Res 1985;56:586-95.

28. Elzinga G, Westerhof N. Matching between ventricle and arterial load. Circ Res 1991;68:1495-500.

29. Ishihara K, Zile MR, Kanazawa S, Tsutsui H, Urabe Y, DeFreyte G, Carabello BA. Left ventricular mechanics and myocyte function after correction of experimental chronic mitral regurgitation by combined mitral valve replacement and preservation of the native mitral valve apparatus. Circulation 1992;86:II-16-25.

30. Hsia HH, Starling MR. Is standardization of left ventricular chamber elastance necessary? Circulation 1990;81:1826-36.

31. Urabe Y, Mann DL, Kent RL, Nakano N, Tomanek RJ, Car abello BA, Cooper G. Cellular and ventricular contractile dysfunction in experimental canine mitral regurgitation. Circ Res 1992;70:131-47.

32. Nakano K, Sugawara M, Ishihara K, Kanazawa S, Corin WJ, Denslow S, Biederman RWW, Carabello BA. Myocardial stiffness derived from end-systolic wall stress and logarithm of reciprocal of wall thickness. Circulation 1990;82:1352-61.

33. Starling MR. Improvement in left ventricular chamber elastance following successful surgery for chronic mitral regurgitation [Abstract]. J Am Coll Cardiol 1992;19:144A.

34. Starling MR. Effects of valve surgery for long-term mitral regurgitation on left ventricular-arterial coupling relations [Abstract]. Circulation 1992;86(suppl 1):54. 